\title{
Systemic therapy for breast cancer and risk of subsequent contralateral breast cancer in the WECARE Study
}

Rikke Langballe ${ }^{1}$, Lene Mellemkjær ${ }^{1 *}$, Kathleen E. Malone ${ }^{2}$, Charles F. Lynch ${ }^{3}$, Esther M. John ${ }^{4,5}$, Julia A. Knight ${ }^{6,7}$, Leslie Bernstein ${ }^{8}$, Jennifer Brooks ${ }^{7}$, Michael Andersson ${ }^{9}$, Anne S. Reiner ${ }^{10}$, Xiaolin Liang ${ }^{10}$, Meghan Woods ${ }^{10}$, Patrick J. Concannon ${ }^{11}$, the WECARE Study Collaborative Group and Jonine L. Bernstein ${ }^{10}$

\begin{abstract}
Background: Treatment with tamoxifen or chemotherapy reduces the risk of contralateral breast cancer (CBC). However, it is uncertain how long the protection lasts and whether the protective effect is modified by patient, tumor, or treatment characteristics.

Methods: The population-based WECARE Study included 1521 cases with CBC and 2212 age- and year of first diagnosis-matched controls with unilateral breast cancer recruited during two phases in the USA, Canada, and Denmark. Women were diagnosed with a first breast cancer before age 55 years during 1985-2008. Abstraction of medical records provided detailed treatment information, while information on risk factors was obtained during telephone interviews. Risk ratios (RRs) and $95 \%$ confidence intervals (Cls) for CBC were obtained from multivariable conditional logistic regression models.

Results: Compared with never users of tamoxifen, the RR of CBC was lower for current users of tamoxifen (RR $=0.73$; $95 \% \mathrm{Cl}=0.55-0.97)$ and for past users within 3 years of last use ( $R R=0.73 ; 95 \% \mathrm{Cl}=0.53-1.00)$. There was no evidence of an increased risk of estrogen receptor-negative CBC associated with ever use of tamoxifen or use for 4.5 or more years. Use of chemotherapy (ever versus never use) was associated with a significantly reduced RR of developing CBC $1-4$ years $(R R=0.59 ; 95 \% \mathrm{Cl}=0.45-0.77)$ and $5-9$ years $(R R=0.73 ; 95 \% \mathrm{Cl}=0.56-0.95)$ after first breast cancer diagnosis. RRs of CBC associated with tamoxifen or with chemotherapy use were independent of age, family history of breast cancer, body mass index and tumor characteristics of the first breast cancer with the exception that the RR of CBC was lower for lobular histology compared with other histologies.

Conclusion: Our findings are consistent with previous studies showing that treatment with tamoxifen or chemotherapy is associated with a lower risk of CBC although the risk reduction appears to last for a limited time period after treatment is completed.
\end{abstract}

Keywords: Breast cancer, Contralateral breast cancer, Tamoxifen, Chemotherapy

\footnotetext{
* Correspondence: lene@cancer.dk

${ }^{1}$ Danish Cancer Society Research Center, Strandboulevarden 49, 2100

Copenhagen, Denmark

Full list of author information is available at the end of the article
} 


\section{Background}

Women who receive tamoxifen or chemotherapy as treatment for breast cancer are at reduced risk of developing contralateral breast cancer (CBC) according to findings from randomized trials $[1,2]$ and observational studies [3-9]. Nonetheless, several unresolved questions regarding these associations remain.

Data on how long the protective effect persists are sparse in relation to tamoxifen [2, 6, 9] and chemotherapy [6]; however, prior studies suggest that the risk reduction may last for up to 10 years following first breast cancer diagnosis. For tamoxifen, the first phase of the WECARE (Women's Environmental, Cancer, and Radiation Epidemiology) Study showed a risk increase beyond 10 years after first breast cancer diagnosis [6]. Duration of tamoxifen treatment may influence the efficacy over time, during periods of active treatment, and afterwards, but this is also understudied [3, 9, 10]. The Early Breast Cancer Trialists' Collaborative Group (EBCTCG) Study published in 2011 demonstrated a protective effect lasting for up to 5 years after ending 5 years of tamoxifen treatment [2]. Regarding risk of estrogen receptor (ER)-specific $\mathrm{CBC}$, one study nested within a registry-based cohort of women with ER-positive breast cancer showed that duration of tamoxifen treatment for 5 or more years was associated with an increased risk of ER-negative second tumors [10].

Some evidence indicates that tamoxifen may only reduce the risk of $\mathrm{CBC}$ for women diagnosed with an ER-positive first tumor [2] and that chemotherapy offers protection against $\mathrm{CBC}$ only for women younger than 50 years at treatment [1]. Both types of systemic therapy have been shown to be protective against $C B C$ in $B R C A 1$ and BRCA2 mutation carriers [11-13]. It is unclear whether other characteristics, such as body mass index (BMI), influence the risk of $\mathrm{CBC}$ associated with systemic breast cancer therapy.

A better understanding of these issues is critical since $\mathrm{CBC}$ is a major concern for breast cancer survivors. Therefore, we analyzed data from the expanded WECARE Study, a large international population-based case-control study of CBC risk following a diagnosis of first primary breast cancer.

\section{Methods}

\section{Study population}

Recruitment and data collection for the WECARE Study were conducted in two phases, herein referred to as WECARE I (2001-2004) and WECARE II (2009-2012). All participants were identified through eight populationbased cancer registries: six in the USA, one in Canada and one in Denmark (Table 1). Selected from a large cohort of women diagnosed with an invasive breast cancer, case patients were diagnosed with $\mathrm{CBC}$ and control patients were diagnosed with unilateral breast cancer.

Cases and controls in WECARE I and II were eligible for inclusion if the first breast cancer was invasive with no disease spread beyond regional lymph nodes and diagnosed during 1985-2008 before age 55 years. Cases were diagnosed with CBC during 1986-2011, and the interval between the first and second diagnoses was at least 1 year in WECARE I and 2 years in WECARE II. Invasive and in-situ CBCs (the latter accounting for $20 \%$ of CBCs) were eligible for WECARE I, whereas only invasive CBCs were included in WECARE II. Cases and controls were individually matched in triplets (one case and two controls) in WECARE I and in pairs in WECARE II by age at first breast cancer (5-year strata), calendar-year of first diagnosis (4-year strata), cancer registry, and race/ethnicity. In WECARE I, for statistical purposes, cases and controls were further counter-matched on radiotherapy so that in each triplet two women had received radiotherapy and one woman had not. The reference date for cases was the $\mathrm{CBC}$ diagnosis date while for controls it was defined by adding the interval between the first breast cancer and $\mathrm{CBC}$ for the matched case to the date of unilateral breast cancer for the control. No other cancer diagnoses, except non-melanoma skin cancer, were allowed up to and including the reference date. The 'at-risk' period was defined as beginning at the date of first cancer diagnosis and ending at the reference date. During this period cases and controls had to reside within the same registry catchment area. Controls were ineligible if they had a prophylactic contralateral mastectomy before the reference date. All participants had to be alive at the time of contact in order to complete a telephone interview and provide a biospecimen.

\section{Data collection}

Information regarding treatment for the first breast cancer and any recurrences during the 'at-risk' period was obtained by abstracting medical records. The recorded information on chemotherapy and hormonal therapy included start and end dates of administration, reason for treatment, and type of drug. If treatment information was unavailable in the medical record, we used selfreported information (for chemotherapy $4 \%$ and for tamoxifen $5 \%$ of all patients).

Medical records were used to obtain information on tumor characteristics (histology, stage, and ER and progesterone receptor (PR) status) for the first breast cancer and the $\mathrm{CBC}$. Information on tumor characteristics was also sought from the cancer registries where available. The telephone interview included questions on known breast cancer risk factors.

A total of 2354 cases and 3599 controls were eligible and invited to participate in the WECARE studies. The 
Table 1 Characteristics of breast cancer patients in the WECARE I and || Study

\begin{tabular}{lll}
\hline Characteristics & CBC cases & UBC controls \\
& $N(\%)$ & $N(\%)$ \\
\hline Overall numbers & $1521(100)$ & $2212(100)$
\end{tabular}

Study area

$\begin{array}{lll}\text { lowa }^{\mathrm{a}} & 201(13) & 314(14) \\ \text { Seattle }^{\mathrm{b}} & 224(15) & 317(14) \\ \text { Ontario }^{c} & 159(10) & 157(7) \\ \text { California }^{\mathrm{d}} & 658(43) & 967(44) \\ \text { Denmark }^{\mathrm{e}} & 279(18) & 457(21)\end{array}$

Age at first breast cancer (years)

$\leq 39$
$40-49$
$50-54$

Age at $\mathrm{CBC} /$ reference date (years)

$\leq 39$
$40-49$
$50-59$
$\geq 60$

Year of diagnosis of first breast cancer

1985-1989

1990-1994

1995-1999

2000-2004

2005-2008

Time since first breast cancer (years)

$1-4$

$5-9$

$\geq 10$

$\begin{array}{ll}268(18) & 384(17) \\ 808(53) & 1180(53) \\ 445(29) & 648(29)\end{array}$

$100(6) \quad 147(7)$

$446(29) \quad 691(31)$

719 (48) $1087(49)$

$256(17) \quad 287(13)$

$303(20) \quad 580(26)$

$572(38) \quad 871(39)$

$426(28) \quad 551(25)$

$186(12) \quad 190(9)$

$34(2) \quad 20(1)$

$586(39) \quad 986(45)$

$574(38) \quad 804(36)$

$361(24) \quad 422(19)$

First-degree family history of breast cancer

Yes

No

Unknown

Lobular histology of first breast cancer

Yes

No

$497(33) \quad 466(21)$

$1004(66) \quad 1706(77)$

$20(1) \quad 40(2)$

$179(12) \quad 223(10)$

$1342(88) \quad 1989(90)$

Stage of first breast cancer

Local

Regional

Unknown

ER/PR status of the first breast cancer

Positive

Negative

Unknown
Table 1 Characteristics of breast cancer patients in the WECARE I and || Study (Continued)

Radiation for first breast cancer ${ }^{f}$

$\begin{array}{lll}\text { Yes } & 880(58) & 1686(76) \\ \text { No } & 641(42) & 525(24) \\ \text { Chemotherapy for first breast cancer } & & \\ \text { Yes } & 822(54) & 1289(58) \\ \text { No } & 699(46) & 923(42) \\ \text { Tamoxifen use for first breast cancer } & & \\ \text { Yes } & 467(31) & 787(36) \\ \text { No } & 1054(69) & 1425(64)\end{array}$

Other endocrine therapy for first breast cancer $^{9}$

$\begin{array}{lll}\text { Yes } & 89(6) & 141(6) \\ \text { No } & 1432(94) & 2071(94)\end{array}$

${ }^{\mathrm{a}}$ The State Health Registry of lowa

${ }^{b}$ Cancer Surveillance System of the Fred Hutchinson Cancer Research Center 'The Ontario Cancer Registry

${ }^{\mathrm{d}}$ Four study centers: 1) Los Angeles County Cancer Surveillance Program, 2) The Cancer Surveillance Program of Orange County/San Diego-Imperial Organization for Cancer Control, 3) Greater Bay Area Cancer Registry (San Francisco Bay Area Region and Santa Clara Region), and 4) Sacramento and Sierra Center Registry (Sacramento Region)

${ }^{\mathrm{e}}$ The Danish Breast Cancer Cooperative Group Database supplemented by the Danish Cancer Registry

Radiation for first breast cancer was unknown for one control

${ }^{9}$ Aromatase inhibitors (67 cases and 99 controls) and other anti-estrogens $C B C$ contralateral breast cancer, ER/PR estrogen receptor/progesterone receptor (if either ER or PR was positive, we considered the ER/PR status as positive), UBC unilateral breast cancer

final number of participants who completed the interview and provided a biospecimen was 1521 (65\%) cases and $2212(62 \%)$ controls. All participants gave written informed consent before enrollment, and the study protocols were approved by the institutional review boards at the University of Iowa (IRB-01), Fred Hutchinson Cancer Research Center, Cancer Prevention Institute of California, University of Southern California, Beckman Research Institute of the City of Hope, University of California at Irvine, Mount Sinai Hospital, Danish Cancer Society and Memorial Sloan Kettering Cancer Center, and by the Committee for the Protection of Human Subjects of the State of California and the ethical committee system in Denmark.

\section{Statistical methods}

We used multivariable-adjusted conditional logistic regression models to estimate risk ratios (RRs) and $95 \%$ confidence intervals (CIs) for $\mathrm{CBC}$ associated with systemic therapy used to treat first primary breast cancer. We estimated the RR for CBC associated with ever use of tamoxifen or chemotherapy versus never use as the reference category. We also calculated RRs associated with time since first breast cancer diagnosis (1-4, $5-9, \geq 10$ years), age at first breast cancer diagnosis $(\leq 39$, 
40-49, 50-54 years), year of first breast cancer diagnosis (1985-1989, 1990-1994, 1995-1999, 2000-2004, 20052008), first-degree family history of breast cancer (yes, no), BMI $\left(<25,25-29.9, \geq 30 \mathrm{~kg} / \mathrm{m}^{2}\right)$, histology (lobular, other), and ER/PR status (positive, negative). If either ER or PR was positive, we considered ER/PR status to be positive. To account for the counter-matching in WECARE I, we included a log-weight covariate offset term. For WECARE II participants who were matched in pairs, we assigned the value of 1 to the offset term.

Analyses of the effects of tamoxifen treatment were stratified by duration of use ( $\leq 18,19-53, \geq 54$ months, or $<54, \geq 54$ months) and by time since last use at reference date (0 (current use at reference date), >0-37 months (past use), $\geq 37$ months (past use)). The cut-point at 37 months was the median for values greater than 0 for controls who received tamoxifen.

We also estimated RRs for ER-positive and ERnegative CBCs separately for ever versus never use of tamoxifen and by duration and time since last use at reference date.

All analyses of associations of risk with tamoxifen treatment were repeated after restricting eligibility to women with a hormone receptor-positive first breast cancer.

For chemotherapy, we examined the association between different regimens and $\mathrm{CBC}$ risk. A woman was classified as having received a chemotherapeutic regimen if she received the combination of the drugs for either her first primary breast cancer or a recurrence (see Table 5 for regime classifications).

Additionally, we examined the RR of CBC for different combinations of breast cancer treatment comparing women to those who only underwent surgery for their first breast cancer. We also performed sensitivity analyses excluding either participants diagnosed with in-situ $\mathrm{CBC}$ or participants diagnosed with recurrences during the 'at-risk' period.

Multivariable models were adjusted for age at first diagnosis, first-degree family history of breast cancer, histology, stage, and ER/PR status of the first breast cancer and radiotherapy. In tamoxifen analyses, we further adjusted for other endocrine therapy and chemotherapy, whereas chemotherapy analyses were adjusted for endocrine therapy.

\section{Results}

The majority of WECARE Study participants were diagnosed with first primary breast cancer during 1990-1999 (Table 1). Twenty-four percent of cases were diagnosed with $\mathrm{CBC} 10$ or more years after the first breast cancer diagnosis. More than half of the participants had a receptor-positive first breast cancer.
Tamoxifen use during the 'at-risk' period was associated with a statistically significant decreased RR of CBC (ever versus never use: $\mathrm{RR}=0.76 ; 95 \% \mathrm{CI}=0.63-0.92$ ) (Table 2). Reduced RRs were seen 1-4 years and 5-9 years after the first breast cancer diagnosis, but not after 10 or more years. However, the RRs of CBC did not differ statistically by time since first breast cancer diagnosis $(P$ heterogeneity $=0.3$ ) or by duration of use (overall $P$ value $=0.7$ ). We found a decreased risk of $\mathrm{CBC}$ for current users of tamoxifen $(\mathrm{RR}=0.73 ; 95 \%$ $\mathrm{CI}=0.55-0.97)$ and for past users who stopped tamoxifen treatment within 37 months before the reference date $(R R=0.73 ; 95 \% C I=0.53-1.00)$; for women who stopped using tamoxifen $\geq 37$ months before the reference date, CBC risk was close to unity (overall $P$ value $=0.2$ ). The $R R$ for current users was lower and only statistically significant for those using tamoxifen for 54 months or longer $(\mathrm{RR}=0.44$; $95 \% \mathrm{CI}=0.27$ $0.73)$ compared with those with shorter use $(\mathrm{RR}=$ 0.86 ; $95 \% \mathrm{CI}=0.62-1.19)$. Within 37 months of ending therapy, there were no statistically significant reductions in $\mathrm{CBC}$ risk for women using tamoxifen for less than 54 months or for women using tamoxifen for 54 months or longer.

We found a statistically significant decreased RR of ER-positive CBC ( $R R=0.75 ; 95 \% \mathrm{CI}=0.58-0.96)$ comparing women treated with tamoxifen with those not receiving tamoxifen treatment (Table 3). The $R R$ of ER-negative $\mathrm{CBC}$ for ever receiving tamoxifen treatment was close to unity ( $R R=0.92 ; 95 \% C I=0.59-1.44)$. There was no increase in the RR of ER-negative $C B C$ for tamoxifen use for $\geq 54$ months either overall $(R R=0.93$; $95 \% \mathrm{CI}=0.50-1.74)$ or when restricting to current users $(\mathrm{RR}=0.76 ; 95 \% \mathrm{CI}=0.25-2.37)$.

No statistically significant differences in associations with $\mathrm{CBC}$ risk were observed for tamoxifen use by age at first breast cancer or year at first breast cancer, family history of breast cancer, BMI or ER/PR status of first breast cancer $(P$ heterogeneity $=0.1-0.9)$ (Table 4$)$. Tamoxifen users with a lobular histology of their first tumor had a more pronounced reduction in $\mathrm{CBC}$ risk than users with other types of tumors $(P$ heterogeneity $=0.03$ ).

Results for women with hormone receptor-positive first tumors (Additional file 1: Tables S1-S4) were similar to the findings for tamoxifen and $\mathrm{CBC}$ risk for all participants, although for the former group a RR of 1.61 (95 \% CI = 0.92-2.79) (Additional file 1: Table S2) was found versus a RR of 1.25 (95\% CI =0.84-1.86) for the latter group (Table 2) for $\geq 54$ months of tamoxifen use ending $\geq 37$ months before the reference date. For ERpositive CBC, RRs of 1.59 (95\% CI =0.94-2.68) (Additional file 1: Table S3) and 1.07 (95 \% CI =0.74-1.56) (Table 3), respectively, were found for these groups if ending treatment $\geq 37$ months before reference date. 
Table 2 Risk ratios of contralateral breast cancer associated with different aspects of tamoxifen use

\begin{tabular}{|c|c|c|c|c|c|}
\hline \multirow[t]{2}{*}{ Use of tamoxifen } & \multirow{2}{*}{$\begin{array}{l}\text { CBC cases } \\
N(\%)\end{array}$} & \multirow{2}{*}{$\begin{array}{l}\text { UBC controls } \\
N(\%)\end{array}$} & \multirow[t]{2}{*}{$\mathrm{RR}^{\mathrm{a}}(95 \% \mathrm{Cl})$} & \multirow[t]{2}{*}{$P$ value } & \multirow[t]{2}{*}{$P$ het. } \\
\hline & & & & & \\
\hline \multicolumn{6}{|l|}{ Tamoxifen use } \\
\hline Never & $1054(69)$ & $1425(64)$ & 1.0 (Referent) & & \\
\hline Ever & $467(31)$ & $787(36)$ & $0.76(0.63-0.92)$ & & \\
\hline \multicolumn{6}{|l|}{ Tamoxifen use according to time since first breast cancer } \\
\hline \multicolumn{6}{|l|}{$1-4$ years } \\
\hline Never & $423(72)$ & $644(65)$ & 1.0 (Referent) & & \\
\hline Ever & $163(28)$ & $342(35)$ & $0.67(0.51-0.88)$ & & \\
\hline \multicolumn{6}{|l|}{$5-9$ years } \\
\hline Never & $387(67)$ & $504(63)$ & 1.0 (Referent) & & \\
\hline Ever & $187(33)$ & $300(37)$ & $0.76(0.57-1.03)$ & & 0.3 \\
\hline \multicolumn{6}{|l|}{$\geq 10$ years } \\
\hline Never & $244(68)$ & $277(66)$ & 1.0 (Referent) & & \\
\hline Ever & $117(32)$ & $145(34)$ & $0.95(0.67-1.34)$ & & \\
\hline Mean duration of tamoxifen (months) & 40.2 & 40.5 & & 0.8 & \\
\hline Median duration of tamoxifen (months) & 44 & 43 & & 0.6 & \\
\hline Interquartile range (months) & $20-60$ & $18-60$ & & & \\
\hline Range (months) & $>0-106$ & $>0-174$ & & & \\
\hline \multicolumn{6}{|l|}{ Duration of tamoxifen use } \\
\hline Never & $1054(69)$ & $1425(64)$ & 1.0 (Referent) & & \\
\hline$\leq 18$ months & $92(6)$ & $165(7)$ & $0.90(0.65-1.24)$ & & \\
\hline 19-53 months & $139(9)$ & $242(11)$ & $0.76(0.57-1.00)$ & $0.7^{\mathrm{e}}$ & \\
\hline$\geq 54$ months & $167(11)$ & $244(11)$ & $0.80(0.61-1.04)$ & & \\
\hline Unknown ${ }^{b}$ & $69(5)$ & $136(6)$ & & & \\
\hline Mean time since last use at reference date for past users (months) & 57.1 & 45.2 & & 0.0001 & \\
\hline Median time since last use at reference date for past users (months) & 48 & 37 & & 0.0001 & \\
\hline Interquartile range (months) & $24-83$ & $13-65$ & & & \\
\hline Range (months) & $1-204$ & $1-186$ & & & \\
\hline \multicolumn{6}{|l|}{ Time since last tamoxifen use at reference date ${ }^{c}$} \\
\hline Never & $1054(69)$ & $1425(64)$ & 1.0 (Referent) & & \\
\hline Current use, 0 months since last use ${ }^{d}$ & $131(9)$ & $249(11)$ & $0.73(0.55-0.97)$ & & \\
\hline Past use, $<37$ months since last use & $110(7)$ & $206(9)$ & $0.73(0.53-1.00)$ & $0.2^{e}$ & \\
\hline Past use, $\geq 37$ months since last use & $161(11)$ & $208(9)$ & $0.98(0.73-1.31)$ & & \\
\hline Unknown ${ }^{\text {b }}$ & $65(4)$ & $124(6)$ & & & \\
\hline \multicolumn{6}{|l|}{ Time since last tamoxifen use at reference date according to duration of use } \\
\hline Never & $1054(69)$ & $1425(64)$ & 1.0 (Referent) & & \\
\hline \multicolumn{6}{|l|}{$<54$ months duration } \\
\hline Current use $e^{d}$ & $101(7)$ & $178(8)$ & $0.86(0.62-1.19)$ & & \\
\hline Past use, $<37$ months since last use & $53(3)$ & $112(5)$ & $0.71(0.47-1.07)$ & & \\
\hline Past use, $\geq 37$ months since last use & $77(5)$ & $117(5)$ & $0.82(0.56-1.19)$ & & \\
\hline
\end{tabular}


Table 2 Risk ratios of contralateral breast cancer associated with different aspects of tamoxifen use (Continued)

\begin{tabular}{|c|c|c|c|}
\hline$\geq 54$ months duration & & & $0.01^{\mathrm{e}}$ \\
\hline Current use $^{d}$ & $28(2)$ & $69(3)$ & $0.44(0.27-0.73)$ \\
\hline Past use, $<37$ months since last use & $56(4)$ & $90(4)$ & $0.71(0.45-1.12)$ \\
\hline Past use, $\geq 37$ months since last use & $83(5)$ & $85(4)$ & $1.25(0.84-1.86)$ \\
\hline Unknown duration ${ }^{b}$ & $69(5)$ & $136(6)$ & \\
\hline $\begin{array}{l}\text { aAdjusted for age at first breast cancer diagno } \\
\text { stage (local, regional, unknown), and estrogen } \\
\text { chemotherapy (yes, no), and other endocrine } \\
\text { bunknown not included in model } \\
{ }^{c} \text { Cut-point at median for values greater than } 0 \\
\text { dCurrent users of tamoxifen at reference date } \\
\text { eOverall P-value }\end{array}$ & & & $\begin{array}{l}\text { n), histology (lobular, otl } \\
\text { n) at first diagnosis, radi }\end{array}$ \\
\hline
\end{tabular}

Use of chemotherapy during the 'at-risk' period versus no chemotherapy was associated with a reduced risk of $\mathrm{CBC}(\mathrm{RR}=0.71 ; 95 \% \mathrm{CI}=0.59-0.85)$ (Table 5). We found statistically significant decreased RRs of CBC associated with chemotherapy $1-4$ years $(\mathrm{RR}=0.59 ; 95 \% \mathrm{CI}=0.45$ $0.77)$ and $5-9$ years $(\mathrm{RR}=0.73 ; 95 \% \mathrm{CI}=0.56-0.95)$ after first diagnosis, whereas no association was found $\geq 10$ years after first diagnosis. There were no statistically significant associations with receipt of chemotherapy by age at first breast cancer or year at first breast cancer, family history of breast cancer, BMI, histology, or ER/PR status of first breast cancer $(P$ heterogeneity $=0.07-0.8)$. We found the largest risk reductions for cyclophosphamide, methotrexate, and fluorouracil (CMF) regimens $(R R=0.67 ; 95 \%$ $\mathrm{CI}=0.54-0.83)$ and other regimens $(\mathrm{RR}=0.55 ; 95 \%$ $\mathrm{CI}=0.31-0.97)($ overall $P$ value $=0.003)($ Table 6$)$.

We found a reduced risk of $\mathrm{CBC}$ for women who were treated with chemotherapy only compared with women who had undergone surgery only $(\mathrm{RR}=0.68 ; 95 \% \mathrm{CI}=$ 0.49-0.93), whereas no association was observed for tamoxifen only $(\mathrm{RR}=1.06 ; 95 \% \quad \mathrm{CI}=0.69-1.64)$ (Table 7). The largest decrease in CBC risk was associated with concurrent administration of chemotherapy, tamoxifen and radiotherapy $(\mathrm{RR}=0.54 ; 95 \% \mathrm{CI}=0.39$ $0.76)$ and non-tamoxifen endocrine therapy used with or without other therapies $(\mathrm{RR}=0.49 ; 95 \% \mathrm{CI}=0.33-0.72)$.

Sensitivity analyses excluding cases diagnosed with insitu CBC or participants diagnosed with recurrences showed no major changes in RR estimates (results not shown).

\section{Discussion}

In the WECARE Study, we showed that reduction in CBC risk was associated with longer duration of tamoxifen use for current users and it continued up to 3 years after ending treatment for past users. There was no increase in risk of ER-negative $C B C$ associated with tamoxifen use for $\geq 54$ months. A CBC risk reduction for up to 10 years after the first breast cancer diagnosis was found for women treated with chemotherapy. We found no evidence that
$\mathrm{CBC}$ risks associated with these systemic treatments differed by age, year of diagnosis, family history of breast cancer, BMI, or ER/PR status, but the association with tamoxifen differed by histology of the first cancer.

In the meta-analysis by the EBCTCG published in 1998, comparing breast cancer clinical trials with different durations of tamoxifen use, reductions in CBC risk were larger in trials of 5 years of tamoxifen use versus those of 1 or 2 years of use [14]. A review published in 1999 of 18 updated trials revealed comparable results [15]. Two casecontrol studies reported no clear difference in CBC risk by duration of tamoxifen use, although the reduction in $\mathrm{CBC}$ risk was only statistically significant when tamoxifen was used for more than 1 year $[3,10]$. One previous cohort study examined duration of use for current users and found similar results [9]. Our finding, that current users of tamoxifen with longer durations of use tend to have the largest $\mathrm{CBC}$ risk reduction, is consistent with longer treatment having a greater impact on risk. Thus, the recent recommendations that tamoxifen should be used for 10 years [16] may also be beneficial in respect to $C B C$ risk.

An important question concerns the length of the protection against $\mathrm{CBC}$ after discontinuation of tamoxifen. The latest EBCTCG meta-analysis from 2011 showed a $\mathrm{CBC}$ risk reduction up to 5-9 years after the first breast cancer diagnosis corresponding to $0-4$ years after ending treatment in trials testing 5 years of tamoxifen versus no tamoxifen [2]. One previous observational study [3] reported an odds ratio of 0.4 up to 1 year after treatment cessation, but no risk reduction was seen more than 1 year after ending treatment. The reduction in $\mathrm{CBC}$ risk in our study continued for 3 years after completion of treatment. This finding is consistent with a preventive effect of tamoxifen on $\mathrm{CBC}$ lasting for a limited time period after ending the treatment. This is in contrast to the most recent prevention trial showing that high-risk women treated with tamoxifen for 5 years continue to have a decreased risk of developing breast cancer throughout the available follow-up of a median of 16.0 years from randomization [17]. 
Table 3 Risk ratios of ER-positive and ER-negative contralateral breast cancer associated with different aspects of tamoxifen use

\begin{tabular}{|c|c|c|c|c|}
\hline \multirow[t]{2}{*}{ Use of tamoxifen } & CBC cases & UBC controls & $\mathrm{RR}^{\mathrm{a}}(95 \% \mathrm{Cl})$ & \multirow[t]{2}{*}{$P$ value } \\
\hline & $N(\%)$ & \multicolumn{2}{|l|}{$N(\%)$} & \\
\hline \multicolumn{5}{|l|}{ ER-positive $C B C^{b}$} \\
\hline Never & $525(63)$ & $692(62)$ & 1.0 (referent) & \\
\hline Ever & $303(37)$ & $421(38)$ & $0.75(0.58-0.96)$ & \\
\hline \multicolumn{5}{|l|}{ Duration of tamoxifen use } \\
\hline Never & $525(63)$ & $692(62)$ & 1.0 (referent) & \\
\hline$<54$ months & $142(17)$ & $198(18)$ & $0.84(0.61-1.15)$ & \\
\hline$\geq 54$ months & $117(14)$ & $149(13)$ & $0.80(0.57-1.12)$ & \\
\hline Unknown ${ }^{c}$ & $44(5)$ & $74(7)$ & & \\
\hline Test for trend & & & & 0.2 \\
\hline Overall $P$ value & & & & 0.3 \\
\hline \multicolumn{5}{|l|}{ Time since last use at reference date } \\
\hline Never & $525(63)$ & $692(62)$ & 1.0 (referent) & \\
\hline Current use, duration $<54$ months & $56(7)$ & $83(7)$ & $0.82(0.52-1.30)$ & \\
\hline Current use, duration $\geq 54$ months & $20(2)$ & $41(4)$ & $0.38(0.20-0.72)$ & \\
\hline Past use, $<37$ months since last use & $68(8)$ & $97(9)$ & $0.72(0.47-1.12)$ & \\
\hline Past use, $\geq 37$ months since last use & $116(14)$ & $131(12)$ & $1.07(0.74-1.56)$ & \\
\hline Unknown ${ }^{c}$ & $43(5)$ & $69(6)$ & & \\
\hline Overall $P$ value & & & & 0.02 \\
\hline \multicolumn{5}{|l|}{ ER-negative $\mathrm{CBC}^{\mathrm{b}}$} \\
\hline Never & $282(78)$ & $318(64)$ & 1.0 (referent) & \\
\hline Ever & $79(22)$ & $180(36)$ & $0.92(0.59-1.44)$ & \\
\hline \multicolumn{5}{|l|}{ Duration of tamoxifen use } \\
\hline Never & $282(78)$ & $318(64)$ & 1.0 (referent) & \\
\hline$<54$ months & $39(11)$ & $87(17)$ & $1.03(0.58-1.82)$ & \\
\hline$\geq 54$ months & $29(8)$ & $58(12)$ & $0.93(0.50-1.74)$ & \\
\hline Unknown ${ }^{c}$ & $11(3)$ & $35(7)$ & & \\
\hline Test for trend & & & & 0.9 \\
\hline Overall $P$ value & & & & 1.0 \\
\hline \multicolumn{5}{|l|}{ Time since last use at reference date } \\
\hline Never & $282(78)$ & $318(64)$ & 1.0 (referent) & \\
\hline Current use, duration $<54$ months & $18(5)$ & $35(7)$ & $1.54(0.68-3.47)$ & \\
\hline Current use, duration $\geq 54$ months & $5(1)$ & $14(3)$ & $0.76(0.25-2.37)$ & \\
\hline Past use, $<37$ months since last use & $21(6)$ & $45(9)$ & $1.12(0.55-2.27)$ & \\
\hline Past use, $\geq 37$ months since last use & $25(7)$ & $55(11)$ & $0.66(0.31-1.42)$ & \\
\hline Unknown ${ }^{c}$ & $10(3)$ & $31(6)$ & & \\
\hline Overall $P$ value & & & & 0.6 \\
\hline
\end{tabular}

$C B C$ contralateral breast cancer, $C I$ confidence intervals, $E R$ estrogen receptor, $R R$ risk ratio, $U B C$ unilateral breast cancer

${ }^{a}$ Adjusted for age at first breast cancer diagnosis (continuous), first-degree family history of breast cancer (yes, no, unknown), histology (lobular, other, unknown), stage (local, regional, unknown) and ER/progesterone receptor status (positive for either, negative, unknown) at first diagnosis, radiation (yes, no), chemotherapy (yes, no), and other endocrine therapy (yes, no)

${ }^{b}$ These models are subset models (two separate models for ER-positive CBC and ER-negative CBC). ER status for CBC was missing for 332 cases

'Unknown not included in model

Although the latest meta-analyses by the EBCTCG showed the preventive effect of tamoxifen on the development of CBC was limited to women with an ER- positive first breast cancer [2], trials initiated before 1990 showed similar CBC risk reductions for patients with ERpoor tumors as for other patients [14]. Similarly, our 
Table 4 Risk ratios of contralateral breast cancer associated with tamoxifen use by patient and tumor characteristics

\begin{tabular}{|c|c|c|c|c|c|c|c|}
\hline & \multicolumn{3}{|c|}{ No tamoxifen } & \multicolumn{3}{|l|}{ Tamoxifen } & \multirow{3}{*}{$P$ het. } \\
\hline & CBC cases & UBC controls & $\overline{\mathrm{RR}}$ & $\overline{\mathrm{CBC}}$ cases & UBC controls & $\mathrm{RR}^{\mathrm{a}}(95 \% \mathrm{Cl})$ & \\
\hline & $N(\%)$ & $N(\%)$ & & $N(\%)$ & $N(\%)$ & & \\
\hline \multicolumn{8}{|c|}{ Age at 1st breast cancer (years) ${ }^{b}$} \\
\hline$\leq 39$ & $222(83)$ & $293(76)$ & 1.0 & $46(17)$ & $91(24)$ & $0.69(0.43-1.10)$ & \multirow{3}{*}{0.9} \\
\hline $40-49$ & $559(69)$ & $782(66)$ & 1.0 & $249(31)$ & $398(34)$ & $0.79(0.62-1.01)$ & \\
\hline $50-54$ & $273(61)$ & $350(54)$ & 1.0 & $172(39)$ & $298(46)$ & $0.75(0.56-1.00)$ & \\
\hline \multicolumn{8}{|c|}{ Year of diagnosis of first breast cancer } \\
\hline 1985-1989 & $250(83)$ & $472(81)$ & 1.0 & $53(17)$ & $108(19)$ & $1.18(0.75-1.87)$ & \multirow{5}{*}{0.1} \\
\hline 1990-1994 & $400(70)$ & $564(65)$ & 1.0 & $172(30)$ & $307(35)$ & $0.86(0.65-1.13)$ & \\
\hline 1995-1999 & $280(66)$ & $306(56)$ & 1.0 & $146(34)$ & $245(44)$ & $0.65(0.48-0.88)$ & \\
\hline 2000-2004 & $101(54)$ & $71(37)$ & 1.0 & $85(46)$ & $119(63)$ & $0.52(0.32-0.85)$ & \\
\hline $2005-2008$ & $23(68)$ & $12(60)$ & 1.0 & $11(32)$ & $8(40)$ & $0.88(0.26-2.92)$ & \\
\hline \multicolumn{8}{|c|}{ First-degree family history of breast cancer ${ }^{c}$} \\
\hline Yes & $344(69)$ & $298(63)$ & 1.0 & $154(31)$ & $172(37)$ & $0.82(0.60-1-12)$ & \multirow{3}{*}{0.7} \\
\hline No & $703(70)$ & $1115(65)$ & 1.0 & $307(30)$ & $602(35)$ & $0.76(0.62-0.94)$ & \\
\hline Unknown ${ }^{d}$ & $7(54)$ & $12(48)$ & 1.0 & $6(46)$ & $13(52)$ & & \\
\hline \multicolumn{8}{|c|}{$\mathrm{BMI}$ at 1 st breast cancer $\left(\mathrm{kg} / \mathrm{m}^{2}\right)$} \\
\hline$<25$ & $749(71)$ & $991(66)$ & 1.0 & $303(29)$ & $506(34)$ & $0.76(0.61-0.95)$ & \multirow{4}{*}{0.9} \\
\hline $25-29.9$ & $191(64)$ & $307(62)$ & 1.0 & $108(36)$ & $189(38)$ & $0.81(0.57-1.15)$ & \\
\hline$\geq 30$ & $111(67)$ & $124(58)$ & 1.0 & $55(33)$ & $91(42)$ & $0.71(0.44-1.14)$ & \\
\hline Unknown $^{d}$ & $3(75)$ & $3(75)$ & 1.0 & $1(25)$ & $1(25)$ & & \\
\hline \multicolumn{8}{|c|}{ Histology of first breast cancer ${ }^{\mathrm{e}}$} \\
\hline Lobular & $112(63)$ & $103(46)$ & 1.0 & $67(37)$ & $120(54)$ & $0.48(0.31-0.75)$ & \multirow[t]{3}{*}{0.03} \\
\hline Other & $940(70)$ & $1,321(67)$ & 1.0 & $398(30)$ & $665(33)$ & $0.82(0.67-0.99)$ & \\
\hline Unknown $^{d}$ & $2(50)$ & $1(33)$ & & $2(50)$ & $2(67)$ & & \\
\hline \multicolumn{8}{|c|}{ ER/PR status of first breast cancer ${ }^{f}$} \\
\hline Positive & $450(52)$ & $679(49)$ & 1.0 & $413(48)$ & $700(51)$ & $0.75(0.60-0.93)$ & \multirow{3}{*}{0.3} \\
\hline Negative & $388(94)$ & $422(89)$ & 1.0 & $25(6)$ & $51(11)$ & $0.54(0.30-0.98)$ & \\
\hline Unknown ${ }^{d}$ & $216(88)$ & $324(90)$ & 1.0 & $29(12)$ & $36(10)$ & & \\
\hline
\end{tabular}

${ }^{a}$ Adjusted for age at first breast cancer diagnosis (continuous), first-degree family history of breast cancer (yes, no, unknown), histology (lobular, other, unknown), stage (local, regional, unknown) and ER/PR status (positive for either, negative, unknown) at first diagnosis, radiation (yes, no), chemotherapy (yes, no), and other endocrine therapy (yes, no)

${ }^{\mathrm{b}} \mathrm{RR}$ are adjusted for all variables listed in footnote "a", except age at first breast cancer diagnosis

${ }^{c} \mathrm{RR}$ are adjusted for all variables listed in footnote "an", except first-degree family history of breast cancer

dUnknown not included in model

${ }^{e} \mathrm{RR}$ are adjusted for all variables listed in footnote "a", except histology of first breast cancer diagnosis

${ }^{f} \mathrm{RR}$ are adjusted for all variables listed in footnote "a", except ER/PR status of first breast cancer diagnosis

$B M I$ body mass index, $C B C$ contralateral breast cancer, $C l$ confidence interval, $E R / P R$ estrogen receptor/progesterone receptor, $P$ het; $P$ value for heterogeneity, $R R$ risk ratio, UBC unilateral breast cancer

results show that treatment with tamoxifen is associated with reduced risk for patients with hormone receptorpositive and for patients with receptor-negative first breast cancers. This would be compatible with $\mathrm{CBCs}$ representing a second independent tumor and not recurrent or metastatic disease [18]. A concern has been raised in two studies by Li et al. $[10,19]$ showing that tamoxifen may increase the risk of ER-negative CBC. The first was a cohort study based on SEER data from western Washington [19], while the second was a nested case-control study within the same study population, although updated with an extended range of diagnosis years, restriction to ER-positive first primary cases, and detailed medical record reviews [10]. The latter study showed that the excess of ERnegative $\mathrm{CBC}$ was confined to patients with $>5$ years of tamoxifen use [10]. Reassuringly, we and a recent cohort study from Geneva [20] were not able to confirm these observations.

Consistent with previous studies, we found that $\mathrm{CBC}$ risk associated with tamoxifen did not differ by age $[2,14]$ 
Table 5 Risk ratios of contralateral breast cancer associated with chemotherapy by time, patient, and tumor characteristics

\begin{tabular}{|c|c|c|c|c|c|c|c|}
\hline & \multicolumn{3}{|c|}{ No chemotherapy } & \multicolumn{3}{|c|}{ Chemotherapy } & \multirow{3}{*}{$P$ het. } \\
\hline & CBC cases & UBC controls & $\overline{\mathrm{RR}}$ & \multirow{2}{*}{$\begin{array}{l}\text { CBC cases } \\
N(\%)\end{array}$} & \multirow{2}{*}{$\begin{array}{l}\text { UBC controls } \\
N(\%)\end{array}$} & \multirow[t]{2}{*}{$\mathrm{RR}^{\mathrm{a}}(95 \% \mathrm{Cl})$} & \\
\hline & $N(\%)$ & $N(\%)$ & & & & & \\
\hline Ever use of chemotherapy (yes/no) & $699(46)$ & $923(42)$ & 1.0 & $822(54)$ & $1,289(58)$ & $0.71(0.59-0.85)$ & \\
\hline \multicolumn{8}{|l|}{ Time since first breast cancer (years) } \\
\hline $1-4$ & $278(47)$ & $402(41)$ & 1.0 & $308(53)$ & $584(59)$ & $0.59(0.45-0.77)$ & \\
\hline $5-9$ & $249(43)$ & $322(40)$ & 1.0 & $325(57)$ & $482(60)$ & $0.73(0.56-0.95)$ & 0.1 \\
\hline$\geq 10$ & $172(48)$ & $199(47)$ & 1.0 & $189(52)$ & $223(53)$ & $0.92(0.65-1.30)$ & \\
\hline \multicolumn{8}{|l|}{ Age at 1st breast cancer (years) ${ }^{b}$} \\
\hline$\leq 39$ & $59(22)$ & $88(23)$ & 1.0 & $209(78)$ & $296(77)$ & $0.99(0.63-1.57)$ & \\
\hline $40-49$ & $372(46)$ & $469(40)$ & 1.0 & $436(54)$ & $711(60)$ & $0.65(0.52-0.82)$ & 0.2 \\
\hline $50-54$ & $268(60)$ & $366(56)$ & 1.0 & $177(40)$ & $282(44)$ & $0.70(0.52-0.94)$ & \\
\hline \multicolumn{8}{|l|}{ Year of diagnosis of first breast cancer } \\
\hline 1985-1989 & $192(63)$ & $295(51)$ & 1.0 & $111(37)$ & $285(49)$ & $0.66(0.46-0.95)$ & \\
\hline 1990-1994 & $283(49)$ & $392(45)$ & 1.0 & $289(51)$ & $479(55)$ & $0.71(0.55-0.92)$ & \\
\hline 1995-1999 & $157(37)$ & $190(34)$ & 1.0 & $269(63)$ & $361(66)$ & $0.79(0.58-1.08)$ & 0.5 \\
\hline 2000-2004 & $58(31)$ & $40(21)$ & 1.0 & $128(69)$ & $150(79)$ & $0.47(0.27-0.83)$ & \\
\hline $2005-2008$ & $9(26)$ & $6(30)$ & 1.0 & $25(74)$ & $14(70)$ & $1.17(0.31-4.43)$ & \\
\hline \multicolumn{8}{|c|}{ First-degree family history of breast cancer ${ }^{c}$} \\
\hline Yes & $219(44)$ & $211(45)$ & 1.0 & $279(56)$ & $259(55)$ & $0.89(0.65-1.20)$ & \\
\hline No & $474(47)$ & $704(41)$ & 1.0 & $536(53)$ & $1,013(59)$ & $0.65(0.53-0.80)$ & 0.07 \\
\hline Unknown $^{d}$ & $6(46)$ & $8(32)$ & 1.0 & $7(54)$ & $17(68)$ & & \\
\hline \multicolumn{8}{|l|}{ BMI at first breast cancer $\left(\mathrm{kg} / \mathrm{m}^{2}\right)$} \\
\hline$<25$ & $538(51)$ & $660(44)$ & 1.0 & $514(49)$ & $837(56)$ & $0.66(0.53-0.81)$ & \\
\hline $25-29.9$ & $107(36)$ & $192(39)$ & 1.0 & $192(64)$ & $304(61)$ & $0.83(0.59-1.18)$ & 0.3 \\
\hline$\geq 30$ & $52(31)$ & $68(32)$ & 1.0 & $114(69)$ & $147(68)$ & $0.89(0.55-1.44)$ & \\
\hline Unknown $^{d}$ & $2(50)$ & $3(75)$ & 1.0 & $2(50)$ & $1(25)$ & & \\
\hline \multicolumn{8}{|l|}{ Histology of first breast cancer ${ }^{\mathrm{e}}$} \\
\hline Lobular & $86(48)$ & $94(42)$ & 1.0 & $93(52)$ & $129(58)$ & $0.77(0.49-1.21)$ & \\
\hline Other & $610(46)$ & $828(42)$ & 1.0 & $728(54)$ & $1,158(58)$ & $0.70(0.58-0.85)$ & 0.7 \\
\hline Unknown $^{d}$ & $3(75)$ & $1(33)$ & & $1(25)$ & $2(67)$ & & \\
\hline \multicolumn{8}{|l|}{ ER/PR status of first breast cancer ${ }^{f}$} \\
\hline Positive & 419 (49) & $609(44)$ & 1.0 & $444(51)$ & $770(56)$ & $0.72(0.57-0.91)$ & \\
\hline Negative & $91(22)$ & $96(20)$ & 1.0 & $322(78)$ & $377(80)$ & $0.67(0.45-1.02)$ & 0.8 \\
\hline Unknown ${ }^{d}$ & $189(77)$ & $218(61)$ & 1.0 & $56(23)$ & $142(39)$ & & \\
\hline
\end{tabular}

${ }^{a}$ Adjusted for age at first breast cancer diagnosis (continuous), first-degree family history of breast cancer (yes, no, unknown), histology (lobular, other, unknown), stage (local, regional, unknown) and ER/PR status (positive for either, negative, unknown) at first breast cancer diagnosis, radiation therapy (yes, no), and endocrine therapy (yes, no)

"RR are adjusted for all variables listed in footnote "a", except age at first breast cancer diagnosis

${ }^{\mathrm{C} R R}$ are adjusted for all variables listed in footnote "a", except first-degree family history of breast cancer

dUnknown not included in model

${ }^{\mathrm{e} R \mathrm{R}}$ are adjusted for all variables listed in footnote "a", except histology of first breast cancer diagnosis

${ }^{f} \mathrm{RR}$ are adjusted for all variables listed in footnote "a", except ER/PR status of first breast cancer diagnosis

$B M I$ body mass index, $C B C$ contralateral breast cancer, $C I$ confidence interval, $E R / P R$ estrogen receptor/progesterone receptor, $P$ het; $P$ value for heterogeneity, $R R$ risk ratio, $U B C$ unilateral breast cancer

or BMI [21]. Studies have shown that tamoxifen might also be effective in $B R C A 1$ and $B R C A 2$ mutation carriers in respect to reducing $\mathrm{CBC}$ risk [11] consistent with our finding of risk reductions regardless of family history of breast cancer. However, due to the higher baseline rate of $\mathrm{CBC}$ for breast cancer patients with family history compared with those with no family history, the absolute numbers prevented would be larger in the former group. 
Table 6 Risk ratios of contralateral breast cancer associated with chemotherapy regimen

\begin{tabular}{|c|c|c|c|c|}
\hline \multirow[t]{2}{*}{ Chemotherapeutic regimen $^{b}$} & \multirow{2}{*}{$\begin{array}{l}\text { CBC cases } \\
N(\%)\end{array}$} & \multicolumn{3}{|l|}{ UBC controls } \\
\hline & & $N(\%)$ & $\mathrm{RR}^{\mathrm{a}}(95 \% \mathrm{Cl})$ & Overall $P$ value \\
\hline No chemotherapy & $699(46)$ & $923(42)$ & 1.00 (Referent) & \\
\hline Taxanes \pm any other chemotherapeutics $^{c}$ & $105(7)$ & $113(5)$ & $0.84(0.57-1.24)$ & \\
\hline Anthracycline-based regimens $^{d}$ & $291(19)$ & $381(17)$ & $0.80(0.62-1.04)$ & 0.003 \\
\hline $\mathrm{CMF}^{\mathrm{e}}$ & $321(21)$ & $629(28)$ & $0.67(0.54-0.83)$ & \\
\hline Other regimens $^{f}$ & $25(2)$ & $55(2)$ & $0.55(0.31-0.97)$ & \\
\hline Unknown ${ }^{9}$ & $80(5)$ & $111(5)$ & & \\
\hline \multicolumn{5}{|c|}{ 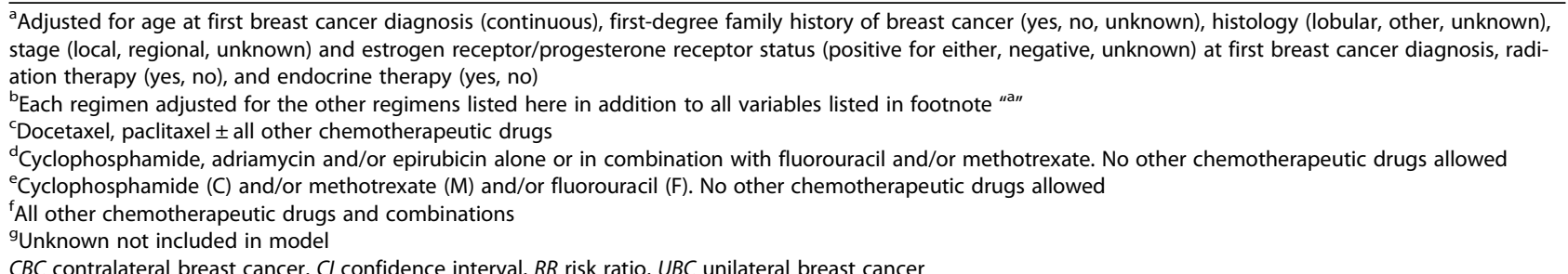 } \\
\hline
\end{tabular}

To our knowledge, no previous studies have investigated whether associations differed by histologic subtype. Therefore, the finding of a lower $\mathrm{CBC}$ risk after tamoxifen use for patients with lobular first breast cancer compared with other types is novel.

Little is known about how chemotherapy affects risk of $\mathrm{CBC}$ over time. Some studies failed to show risks deviating from unity during both short- and long-term time intervals after first breast cancer [5, 22]. A study from the Netherlands reported an overall reduction in $\mathrm{CBC}$ after chemotherapy; however, for 5-year survivors followed up to 15 years, no significant risk reduction was seen [4]. Our study suggests that the protective effect of chemotherapy on CBC persists for up to 10 years after the first breast cancer diagnosis.

In the 2005 EBCTCG meta-analysis, the beneficial effects of chemotherapy on $\mathrm{CBC}$ were restricted to younger women [1]. We were able to confirm this finding in the WECARE Study as all our participants were younger than 55 years at first breast cancer diagnosis; however, we found no tendency towards a lower risk by decreasing age. Also, in the 2005 EBCTCG study, a significant reduction in $\mathrm{CBC}$ risk was observed for women below age 50 years treated with CMF regimens but not with anthracycline regimens [1]. In the latest EBCTCG update from 2012, no significant effect of either

Table 7 Risk ratios of contralateral breast cancer associated with different combinations of breast cancer treatment

\begin{tabular}{llll}
\hline Treatment for first breast cancer $^{\mathrm{a}}$ & CBC cases & UBC controls & \\
\hline Surgery alone & $N(\%)$ & $N(\%)$ & RR $^{\mathrm{b}}(95 \% \mathrm{Cl})$ \\
Chemotherapy alone & $249(16)$ & $156(7)$ & 1.00 (Referent) \\
Tamoxifen alone & $209(14)$ & $197(9)$ & $0.68(0.49-0.93)$ \\
Radiotherapy alone & $81(5)$ & $58(3)$ & $1.06(0.69-1.64)$ \\
Chemotherapy + tamoxifen & $244(16)$ & $470(21)$ & $1.13(0.88-1.47)$ \\
Chemotherapy + radiotherapy & $81(5)$ & $83(4)$ & $0.70(0.47-1.05)$ \\
Tamoxifen + radiotherapy & $319(21)$ & $569(26)$ & $0.82(0.62-1.09)$ \\
Chemotherapy + tamoxifen + radiotherapy & $107(7)$ & $208(9)$ & $0.83(0.60-1.16)$ \\
Other endocrine therapy ${ }^{\mathrm{c}} \pm$ other treatment & $142(9)$ & $329(15)$ & $0.54(0.39-0.76)$ \\
One treatment or more unknown & $89(6)$ & $141(6)$ & $0.49(0.33-0.72)$
\end{tabular}

\footnotetext{
${ }^{a}$ All treatment categories include surgery
}

${ }^{\mathrm{b}}$ Adjusted for all variables in the Table plus age at first breast cancer diagnosis (continuous), first-degree family history of breast cancer (yes, no, unknown), histology (lobular, other, unknown), stage (local, regional, unknown), and estrogen receptor/progesterone receptor status (positive for either, negative, unknown) at first breast cancer diagnosis

'Includes aromatase inhibitors (67 cases and 99 controls) and other anti-estrogens

$\mathrm{d} P$ value overall $=0.002$ if the category "Radiotherapy alone" is removed from the model

$C B C$ contralateral breast cancer, $C I$ confidence interval, $R R$ risk ratio, $U B C$ unilateral breast cancer 
anthracycline or CMF regimens was found; however, these analyses were not age-stratified [23]. In the WECARE Study, we also observed little difference in CBC risk by chemotherapy regimen, although the clearest risk reduction was seen for CMF regimens.

The strengths of our study include the populationbased study design, the large sample size of women diagnosed with $\mathrm{CBC}$, and the detailed information on treatment obtained from medical records. This enabled us to adjust for other endocrine therapy including aromatase-inhibitors that have been shown to be more effective than tamoxifen in preventing CBC [24]. However, some limitations exist. First, our study was not a randomized trial where treatment would be randomly assigned. Also, women with breast cancer survived until recruitment into the study, and we cannot exclude the possibility that they may differ from otherwise eligible women who were deceased. There was no reduction in $\mathrm{CBC}$ risk for women using only tamoxifen and no other treatments; however, this was a relatively small and distinct group. We cannot rule out the possibility that a small fraction of $\mathrm{CBCs}$ were actually metastases. However, we restricted the underlying cohort of breast cancer patients to those without distant spread at first diagnosis, and the sensitivity analyses suggested that inclusion of participants with recurrences before the $\mathrm{CBC}$ diagnosis did not substantially affect our results.

\section{Conclusion}

In conclusion, the expanded WECARE data suggest that treatment with tamoxifen or chemotherapy may offer protection against a $\mathrm{CBC}$ for a limited period following completion of treatment. Previously raised concerns that tamoxifen may increase risk of ER-negative CBC could not be substantiated.

\section{Additional file}

Additional file 1: Table S1. Characteristics of patients diagnosed with ER/PR-positive first breast cancer enrolled in the WECARE I and II Study. Table S2. Risk ratios of contralateral breast cancer associated with different aspects of tamoxifen use among participants diagnosed with ER/PR positive first breast cancer in the WECARE I and II Study. Table S3. Risk ratios of ER-positive and ER-negative contralateral breast cancer associated with different aspects of tamoxifen use among participants diagnosed with ER/PR-positive first breast cancer in the WECARE I and II Study. Table S4. Risk ratios of contralateral breast cancer associated with tamoxifen use by patient and tumor characteristics among participants diagnosed with ER/PR positive first breast cancer in the WECARE I and II Study. (DOCX 59 kb)

\section{Abbreviations}

$\mathrm{BMI}$, body mass index; $\mathrm{CBC}$, contralateral breast cancer; $\mathrm{Cl}$, confidence interval; CMF, cyclophosphamide, methotrexate, and fluorouracil; $E R$, estrogen receptor; PR, progesterone receptor; $\mathrm{RR}$, risk ratio

\section{Acknowledgements}

The authors are grateful to all women who participated in the WECARE studies and the WECARE Study Collaborative Group for their invaluable contributions:

Memorial Sloan Kettering Cancer Center (Coordinating Center) Investigators and Staff: Jonine L. Bernstein Ph.D. (WECARE Study P.I.); Marinela Capanu Ph.D.; Xiaolin Liang M.D.; Irene Orlow Ph.D.; Anne S. Reiner M.P.H.; Mark Robson, M.D.; Meghan Woods M.P.H.

Collaborative Site Investigators: Leslie Bernstein Ph.D., Beckman Research Institute of the City of Hope, Duarte, CA, USA; John D. Boice Jr. Sc.D., National Council on Radiation Protection and Measurements, Bethesda, MD, USA, and Vanderbilt University, Nashville, TN, USA; Jennifer Brooks Ph.D., University of Toronto, Ontario, Canada; Patrick J Concannon Ph.D., University of Florida, Gainesville, FL, USA; Duncan C. Thomas Ph.D., Daniel O. Stram Ph.D. and Dave V. Conti Ph.D., University of Southern California, Los Angeles, CA, USA; David Duggan Ph.D., Translational Genomics Research Institute, (TGen), Phoenix, AZ, USA; Esther M John Ph.D., M.S.P.H., Cancer Prevention Institute of California, Fremont, CA, USA, and Stanford University School of Medicine, Stanford, CA, USA; Robert W. Haile Dr.P.H., Stanford University School of Medicine, Stanford, CA, USA; Julia A. Knight Ph.D., LunenfeldTanenbaum Research Institute, Sinai Health System, Toronto, Canada; Charles F. Lynch M.D., Ph.D.; University of lowa, lowa City, IA, USA; Kathleen E. Malone Ph.D., Fred Hutchinson Cancer Research Center, Seattle, WA, USA; Lene Mellemkjær Ph.D. and Jørgen H. Olsen M.D. DMSc., Danish Cancer Society Research Center, Copenhagen, Denmark; Daniela Seminara Ph.D. M.P.H. and Joanne W. Elena Ph.D., M.P.H., National Cancer Institute, Bethesda, MD, USA; Roy E. Shore Ph.D., Dr.P.H., New York University, New York, NY, USA; Marilyn Stovall Ph.D., University of Texas MD Anderson Cancer Center, Houston, TX, USA; Marc Tischkowitz M.D., Ph.D., University of Cambridge, Cambridge, UK. Collaborative Site Staff: Kristina Blackmore M.Sc., Lunenfeld-Tanenbaum Research Institute, Sinai Health System, Toronto, Canada; Anh T. Diep, Stanford University, Palo Alto, CA, USA; Judy Goldstein B.A., Cancer Prevention Institute of California, Fremont, CA, USA; Rikke Langballe M.P.H., Danish Cancer Society Research Center, Copenhagen, Denmark; Cecilia O'Brien, Fred Hutchinson Cancer Research Center, Seattle, WA, USA; Susan Smith M.P.H., Rita Weathers M.S. and Irene Harris B.S., C.M.D., University of Texas MD Anderson Cancer Center, Houston, TX, USA; Michele West Ph.D., University of lowa, lowa City, IA, USA.

\section{Funding}

The research was supported by National Institutes of Health (grant number CA129639, CA083178, CA097397, CA114236, CA008748), and the Scientific Committee of the Danish Cancer Society (grant no. R90-A5792-14-S2).The funding sources had no role in the design, in the collection, analysis, or interpretation of data, in the writing of the manuscript, or in the decision to submit the manuscript for publication.

\section{Authors' contributions}

$L M, K E M, C F L, E M J, J A K, L B, P C$, and JLB contributed to the conception and design of the study. RL, $L M, K E M, C F L, E M J, J A K, L B, J B, M A$, $X L$, and $M W$ were involved in data collection. $\mathrm{JB}, \mathrm{XL}, \mathrm{MW}$, and JLB participated in the coordination of the study. AR conducted the statistical analysis. RL drafted the first version of the manuscript in cooperation with LM. All authors contributed to the interpretation of the results, provided critical revision on the draft manuscript for important intellectual content, and approved the final version of the manuscript.

\section{Competing interests}

The authors declare that they have no competing interests.

\section{Author details}

${ }^{1}$ Danish Cancer Society Research Center, Strandboulevarden 49, 2100 Copenhagen, Denmark. ${ }^{2}$ Fred Hutchinson Cancer Research Center, Seattle, WA, USA. ${ }^{3}$ University of lowa, lowa City, IA, USA. ${ }^{4}$ Cancer Prevention Institute of California, Fremont, CA, USA. ${ }^{5}$ Department of Health Research and Policy (Epidemiology) and Stanford Cancer Institute, Stanford University School of Medicine, Stanford, CA, USA. ${ }^{6}$ Lunenfeld-Tanenbaum Research Institute, Sinai Health System, Toronto, Canada. ${ }^{7}$ University of Toronto, Dalla Lana School of Public Health, Toronto, Canada. ${ }^{8}$ Beckman Research Institute of the City of Hope, Duarte, CA, USA. ${ }^{9}$ Department of Oncology at Rigshospitalet, 
Copenhagen, Denmark. ${ }^{10}$ Memorial Sloan Kettering Cancer Center, New York, NY, USA. ${ }^{11}$ University of Florida Genetics Institute, Gainesville, FL, USA.

Received: 15 December 2015 Accepted: 31 May 2016 Published online: 12 July 2016

\section{References}

1. Early Breast Cancer Trialists' Collaborative Group (EBCTCG). Effects of chemotherapy and hormonal therapy for early breast cancer on recurrence and 15-year survival: an overview of the randomised trials. Lancet. 2005; 365(9472):1687-717.

2. Early Breast Cancer Trialists' Collaborative Group (EBCTCG), Davies C, Godwin J, Gray R, Clarke M, Cutter D, et al. Relevance of breast cancer hormone receptors and other factors to the efficacy of adjuvant tamoxifen: patient-level meta-analysis of randomised trials. Lancet. 2011;378(9793):771-84. doi:10.1016/S0140-6736(11)60993-8.

3. Cook LS, Weiss NS, Schwartz SM, White E, MCKnight B, Moore DE, et al. Population-based study of tamoxifen therapy and subsequent ovarian, endometrial, and breast cancers. J Natl Cancer Inst. 1995;87(18):1359-64.

4. Schaapveld M, Visser O, Louwman WJ, Willemse PH, de Vries EG, van der Graaf WT, et al. The impact of adjuvant therapy on contralateral breast cancer risk and the prognostic significance of contralateral breast cancer: a population based study in the Netherlands. Breast Cancer Res Treat. 2008;110(1):189-97.

5. Hooning MJ, Aleman BM, Hauptmann M, Baaijens MH, Klijn JG, Noyon R, et al. Roles of radiotherapy and chemotherapy in the development of contralateral breast cancer. J Clin Oncol. 2008;26(34):5561-8.

6. Bertelsen L, Bernstein L, Olsen JH, Mellemkjaer L, Haile RW, Lynch CF, et al. Effect of systemic adjuvant treatment on risk for contralateral breast cancer in the Women's Environment, Cancer and Radiation Epidemiology Study. J Natl Cancer Inst. 2008;100(1):32-40.

7. Vichapat V, Garmo H, Holmqvist M, Liljegren G, Warnberg F, Lambe M, et al. Tumor stage affects risk and prognosis of contralateral breast cancer: results from a large Swedish-population-based study. J Clin Oncol. 2012;30(28):3478-85.

8. Newcomb PA, Solomon C, White E. Tamoxifen and risk of large bowel cancer in women with breast cancer. Breast Cancer Res Treat. 1999;53(3):271-7.

9. Mellemkjaer L, Steding-Jessen M, Frederiksen K, Andersson M, Ejlertsen B, Jensen $\mathrm{MB}$, et al. Risk of contralateral breast cancer after tamoxifen use among Danish women. Ann Epidemiol. 2014;24(11):843-8. doi:10.1016/j.annepidem.2014.08.003.

10. Li Cl, Daling JR, Porter PL, Tang MT, Malone KE. Adjuvant hormonal therapy for breast cancer and risk of hormone receptor-specific subtypes of contralateral breast cancer. Cancer Res. 2009;69(17):6865-70.

11. Xu L, Zhao Y, Chen Z, Wang Y, Chen L, Wang S. Tamoxifen and risk of contralateral breast cancer among women with inherited mutations in BRCA1 and BRCA2: a meta-analysis. Breast Cancer. 2015. doi:10.1007/s12282-015-0619-6.

12. Reding KW, Bernstein JL, Langholz BM, Bernstein L, Haile RW, Begg CB, et al. Adjuvant systemic therapy for breast cancer in BRCA1/BRCA2 mutation carriers in a population-based study of risk of contralateral breast cancer. Breast Cancer Res Treat. 2010;123(2):491-8. doi:10.1007/s10549-010-0769-3.

13. Narod SA, Brunet JS, Ghadirian P, Robson M, Heimdal K, Neuhausen SL, et al. Tamoxifen and risk of contralateral breast cancer in BRCA1 and BRCA2 mutation carriers: a case-control study. Hereditary Breast Cancer Clinical Study Group. Lancet. 2000;356(9245):1876-81.

14. Early Breast Cancer Trialists' Collaborative Group. Tamoxifen for early breast cancer: an overview of the randomised trials. Lancet. 1998;351(9114):1451-67.

15. O'Regan R, Jordan VC, Gradishar WJ. Tamoxifen and contralateral breast cancer. J Am Coll Surg. 1999;188(6):678-83.

16. Burstein $H J$, Temin $S$, Anderson H, Buchholz TA, Davidson NE, Gelmon KE, et al. Adjuvant endocrine therapy for women with hormone receptorpositive breast cancer: American Society of Clinical Oncology clinical practice guideline focused update. J Clin Oncol. 2014;32(21):2255-69. doi:10.1200/JCO.2013.54.2258

17. Cuzick J, Sestak I, Cawthorn S, Hamed H, Holli K, Howell A, et al. Tamoxifen for prevention of breast cancer: extended long-term follow-up of the IBIS-I breast cancer prevention trial. Lancet Oncol. 2015;16(1):67-75. doi:10.1016/S1470-2045(14)71171-4.

18. Swain SM, Wilson JW, Mamounas EP, Bryant J, Wickerham DL, Fisher B, et al. Estrogen receptor status of primary breast cancer is predictive of estrogen receptor status of contralateral breast cancer. J Natl Cancer Inst. 2004;96(7):516-23.

19. Li Cl, Malone KE, Weiss NS, Daling JR. Tamoxifen therapy for primary breast cancer and risk of contralateral breast cancer. J Natl Cancer Inst. 2001;93(13):1008-13.

20. Bouchardy C, Benhamou S, Fioretta G, Verkooijen HM, Chappuis PO, Neyroud-Caspar I, et al. Risk of second breast cancer according to estrogen receptor status and family history. Breast Cancer Res Treat. 2011;127(1):233-41.

21. Dignam JJ, Wieand K, Johnson KA, Fisher B, Xu L, Mamounas EP. Obesity, tamoxifen use, and outcomes in women with estrogen receptor-positive early-stage breast cancer. J Natl Cancer Inst. 2003;95(19):1467-76.

22. Cook LS, White E, Schwartz SM, McKnight B, Daling JR, Weiss NS. A population-based study of contralateral breast cancer following a first primary breast cancer (Washington, United States). Cancer Causes Control. 1996;7(3):382-90.

23. Early Breast Cancer Trialists' Collaborative Group (EBCTCG), Peto R, Davies $C$, Godwin J, Gray R, Pan HC, et al. Comparisons between different polychemotherapy regimens for early breast cancer: meta-analyses of long-term outcome among 100,000 women in 123 randomised trials. Lancet. 2012;379(9814):432-44. doi:10.1016/S0140-6736(11)61625-5.

24. Early Breast Cancer Trialists' Collaborative Group (EBCTCG), Dowsett M, Forbes JF, Bradley R, Ingle J, Aihara T, et al. Aromatase inhibitors versus tamoxifen in early breast cancer: patient-level meta-analysis of the randomised trials. Lancet. 2015;386(10001):1341-52. doi:10.1016/S0140-6736(15)61074-1.

\section{Submit your next manuscript to BioMed Central and we will help you at every step:}

- We accept pre-submission inquiries

- Our selector tool helps you to find the most relevant journal

- We provide round the clock customer support

- Convenient online submission

- Thorough peer review

- Inclusion in PubMed and all major indexing services

- Maximum visibility for your research

Submit your manuscript at www.biomedcentral.com/submit
Biomed Central 